\title{
A cross-sectional study on the correlation between postnatal foot length and various other anthropometric parameters along with the gestational age
}

\author{
Arun Raj A. ${ }^{1}$, Maheswari K. ${ }^{2 *}$
}

DOI: https://doi.org/10.17511/ijpr.2020.i08.04

\footnotetext{
1 Abhinaya Arun Raj, Junior resident, Department of Paediatrics, Sri Venkateshwaraa Medical College Hospital and Research Centre, Puducherry, India.

${ }^{2 *}$ K. Maheswari, Professor, Department of Paediatrics, Sri Venkateshwaraa Medical College Hospital and Research Centre, Puducherry, India.
}

Introduction: This study was done to assess the utility of foot length in determining the anthropometric parameters of a newborn in a tertiary care teaching hospital. Materials and Methods: This cross-sectional study among 270 newborns were done at Sri Venkateswaraa medical college hospital and research centre, from Nov 2018 to May 2020. All the healthy live newborns were taken into the study and newborns with congenital lower limb anomalies were excluded. Results: The mean birth weight of the neonate $2.948 \pm 0.344 \mathrm{~kg}$ which ranged from $2.050 \mathrm{~kg}$ to $3.750 \mathrm{~kg}$. The mean foot length, head circumference and chest circumference of the foot length was $8.113 \pm 0.468 \mathrm{~cm}, 48.989 \pm 1.093 \mathrm{~cm}, 34.437 \pm 0.659 \mathrm{~cm}$ and $32.372 \pm 0.734 \mathrm{~cm}$ respectively. The foot length had a maximum correlation with birth weight $(r$-value $=0.905)$ followed by gestational age $(r-$ value $=0.809)$, length $(r$-value $=0.786)$, head circumference $(r$-value $=0.719)$ and chest circumference ( $r$-value $=0.603$ ). Conclusion: Foot length had a significant correlation with birth weight and gestational age of the neonates. Foot length also correlated significantly with other anthropometric variables like length, head circumference and chest circumference.

Keywords: Newborn, Low birth weight (LBW), Term, Preterm, Foot length (FL), Gestational age $(\mathrm{GA})$, Head circumference (HC), Chest circumference (CC)

Corresponding Author

K. Maheswari, Professor, Department of Paediatrics, Sri Venkateshwaraa Medical College Hospital and Research Centre, Puducherry, India. Email: maheswarijipmer@gmail.com
How to Cite this Article

To Browse

Raj AA., Maheswari K. A cross-sectional study on the correlation between postnatal foot length and various other anthropometric parameters along with the gestational age. Pediatric Rev Int J Pediatr Res. $2020 ; 7(8): 414-419$.

Available From

https://pediatrics.medresearch.in/index.php/ijpr/arti

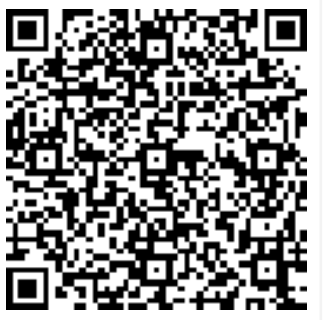
cle/view/638

Manuscript Received 2020-11-28

Conflict of Interest No
Review Round 1 2020-12-03

Funding

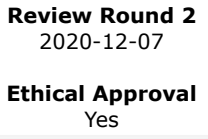

Review Round 3

Accepted 2020-12-09

Plagiarism $X$-checker $8 \%$

Note Open Access article licensed under a Creative Commons Attribution 4.0 International License https://creativecommons.org/licenses/by/4.0/ unported [CC BY 4.0]. 


\section{Introduction}

Neonatal period is the most vulnerable period of life. Worldwide there were 2.5 million neonatal deaths in 2018. Every day, 7,000 newborn deaths are happening which account for $47 \%$ of all deaths among under 5 children. $7 \%$ of neonatal death occurs during the first week of life and 1 million deaths occur within the first 24 hours of life. The main causes of neonatal deaths are LBW, prematurity, infections, birth trauma, accounting for $80 \%$ of neonatal deaths [1]. Birth weight is the single most important criterion for determining neonatal and infant survival. Low birth weight is a sensitive indicator of socioeconomic conditions and indirectly measures the health of the mother and child. Babies with a birth weight of less than $2500 \mathrm{gm}$ irrespective of the period of gestation are termed as LBW babies [2]. In India 30-35\% of babies are LBW and more than half of these LBW newborns are full-term babies [3]. LBW includes preterm babies born before 37 weeks of gestation as well as infants of any gestation who are small for dates due to intrauterine growth retardation [4]. In developing countries, most of the deliveries are conducted at a peripheral level where accurate weight and assessment of gestational age becomes difficult because of non-availability of weighing machines, ultrasonography and trained personnel. Simple anthropometric alternatives to measure birth weight have been investigated in various settings to help identify low birth weight and preterm babies [5]

Foot length is quite simple to measure as the only requirement for it is a well-calibrated ruler or a tape. Thus this study was done to find out the correlation between $\mathrm{FL}$ and other anthropometric variables namely Birth weight(BW), Gestational age (GA), Head circumference (HC), Chest circumference (CC) and length and to determine the utility of using newborn FL as a screening tool to identify LBW/Preterm babies.

\section{Materials and Methods}

Study design: The present study is a crosssectional hospital-based study

Setting: Hospital-based study in a tertiary care teaching hospital in Puducherry.

Participants: 270 newborns taken during the period of study, November 2018 to May 2020.
Inclusion criteria: All healthy live newborns were included in the study. All newborns of all the gestational age which included preterm, term and post-term who were delivered in the $\mathrm{SVMCH}$ within 48 hours of life were taken into the study.

Exclusion criteria: newborns with lower limb congenital anomalies were excluded

\section{Variables:}

Foot length (FL): . The foot length of the right foot was measured by a stiff plastic transparent ruler to the nearest of $0.05 \mathrm{~cm}$ thrice and the average was recorded. The measurement was taken by fixing the tip of the heel to the zero marks of the ruler and after straightening the foot and toes, the foot length measurement was recorded, the other end being the tip of the great toe or second toe (whichever was the longer length).

Birth weight (BW): Babies were weighed naked on an electronic weighing machine which was being used at NICU, in Sri Venkateswaraa Medical College Hospital And Research Centre within 24 hours of birth.

Length: Length was recorded to the nearest of 0.1 $\mathrm{cm}$ on an infantometer with the baby in the supine position, knees fully extended and soles of the feet held firmly against the footboard and head touching the fixed board.

Head circumference (HC): Head circumference was measured by placing the measuring tape anteriorly at the glabella and posteriorly along with the most prominent point.

Chest circumference (CC): Chest circumference was measured at the level of nipples by measuring tape to the nearest of $0.1 \mathrm{~cm}$. The gestational age of the babies was determined by new Ballard scoring

Data source: A history from mother, newborn examination and other details from patient case sheet

\section{Study size: 270}

Statistical analysis: The anthropometrical measures of newborn babies were presented as frequency and percentage for qualitative data. Mean and the standard deviation was used for quantitative data. Quantitative data were compared using Student's t-test. The correlation was done to examine the linear relationship between two continuous variables. $\mathrm{p}$ value $<0.05$ was considered as siqnificant. 


\section{Results}

This was a cross-sectional study conducted in the Department of Pediatrics, Sri Venkateswaraa Medical College Hospital and Research Centre. The study period was conducted from November 2018 to May 2020.

Table-1: Distribution of the hours of life, gestational age, birth weight category of the study population.

\begin{tabular}{|l|l|l|}
\hline \multicolumn{1}{|c|}{ Hours of life } & Frequency & Percent \\
\hline $0-12$ hours & 126 & 46.7 \\
\hline $13-24$ hours & 92 & 34.1 \\
\hline $25-36$ hours & 29 & 10.7 \\
\hline $37-48$ hours & 23 & 8.5 \\
\hline Total & 270 & 100 \\
\hline Gestational age category & \multicolumn{2}{l|}{} \\
\hline Preterm $(<37$ weeks $)$ & 33 & 12.2 \\
\hline Term $(>/=37$ weeks $)$ & 237 & 87.8 \\
\hline Total & 270 & 100.0 \\
\hline Birth weight category & \multicolumn{2}{|l}{} \\
\hline Low birth weight $(<2.500 \mathrm{~kg})$ & 27 & 10.0 \\
\hline Normal birth weight $(>/=2.500 \mathrm{~kg})$ & 243 & 90.0 \\
\hline Total & 270 & 100.0 \\
\hline
\end{tabular}

Out of 270 babies, 112 babies were female and 158 were male. In the present study, $12.2 \%$ of the neonates were found to be preterm babies and $87.8 \%$ of the neonates were term babies as given in table 1 . More of the study population was less than 24 hours of life. In the present study, $10 \%$ of the neonates were found to have low birth weight and $90 \%$ of the neonates had normal birth weight (Table 1) In the present study, $12.2 \%$ of the neonates were found to be preterm babies and $87.8 \%$ of the neonates were term babies (Table 1 ).

Table-2: Distribution of the anthropometric parameters and gestational age of the neonates.

\begin{tabular}{|l|l|l|l|l|}
\hline \multicolumn{1}{|c|}{ Parameters } & Minimum & Maximum & Mean & Std. Deviation \\
\hline Foot length $(\mathrm{cm})$ & 7.100 & 8.900 & 8.113 & 0.468 \\
\hline Birth wt $(\mathrm{kg})$ & 2.050 & 3.750 & 2.948 & 0.344 \\
\hline Length $(\mathrm{cm})$ & 46.000 & 50.000 & 48.989 & 1.093 \\
\hline Head circumference $(\mathrm{cm})$ & 32.000 & 35.500 & 34.437 & 0.659 \\
\hline Chest circumference $(\mathrm{cm})$ & 30.500 & 34.000 & 32.372 & 0.734 \\
\hline Gestational age (weeks) & 34.286 & 41.286 & 38.432 & 1.395 \\
\hline
\end{tabular}

In the present study, the mean foot length was $8.113 \pm 0.468 \mathrm{~cm}$ which ranged from 7.100 to 8.900 $\mathrm{cm}$. The mean values of other anthropometric variables in the present study were as follows:
Length $48.989 \pm 1.093 \mathrm{~cm}$; head circumference $34.437 \pm 0.659 \mathrm{~cm}$ and chest circumference $32.372 \pm 0.734 \mathrm{~cm}$. The mean gestational age of the neonates was $38.432 \pm 1.395$ weeks which ranged from 34.286 weeks to 41.286 weeks (Table 2 ).

Table-3: Correlation between birth weight and other anthropometric parameters of the neonates.

\begin{tabular}{|c|c|c|c|c|}
\hline Parameters & $\begin{array}{l}\text { Number of } \\
\text { subjects }\end{array}$ & $\begin{array}{l}\text { Correlation } \\
\text { (r) }\end{array}$ & $\begin{array}{c}\text { R-square } \\
\text { (r2) }\end{array}$ & $\mid \mathrm{p}$ \\
\hline Length $(\mathrm{cm})$ & 270 & 0.823 & 0.677 & $\begin{array}{l}<0.00 \\
1\end{array}$ \\
\hline $\begin{array}{l}\text { Head circumference } \\
(\mathrm{cm})\end{array}$ & 270 & 0.763 & 0.582 & $\begin{array}{l}<0.00 \\
1 \\
\end{array}$ \\
\hline $\begin{array}{l}\text { Chest circumference } \\
(\mathrm{cm})\end{array}$ & 270 & 0.675 & 0.456 & $\begin{array}{l}<0.00 \\
1\end{array}$ \\
\hline Foot length $(\mathrm{cm})$ & 270 & 0.905 & 0.819 & $\begin{array}{l}<0.00 \\
1\end{array}$ \\
\hline
\end{tabular}

The birth weight showed a significant statistical correlation with length, head circumference, chest circumference and foot length. All the parameters showed a positive correlation coefficient ( $r$-value). The maximum correlation was observed with foot length $(r$-value $=0.905)$ followed by length ( $r$ value $=0.823$ ) as given in Table 3 .

Table-4: Correlation between gestational age and other anthropometric parameters of the neonates.

\begin{tabular}{|c|c|c|c|c|}
\hline Parameters & $\begin{array}{l}\text { Number of } \\
\text { subjects }\end{array}$ & $\begin{array}{c}\text { Correlation } \\
\text { (r) }\end{array}$ & $\begin{array}{c}\text { R-square } \\
\text { (r2) }\end{array}$ & $\begin{array}{c}\mathrm{p} \\
\text { value }\end{array}$ \\
\hline Length $(\mathrm{cm})$ & 270 & 0.853 & 0.728 & $\begin{array}{l}<0.00 \\
1\end{array}$ \\
\hline $\begin{array}{l}\text { Head circumference } \\
(\mathrm{cm})\end{array}$ & 270 & 0.794 & 0.630 & $\begin{array}{l}<0.00 \\
1\end{array}$ \\
\hline $\begin{array}{l}\text { Chest circumference } \\
(\mathrm{cm})\end{array}$ & 270 & 0.730 & 0.533 & $\begin{array}{l}<0.00 \\
1\end{array}$ \\
\hline Foot length $(\mathrm{cm})$ & 270 & 0.809 & 0.654 & $\begin{array}{l}<0.00 \\
1\end{array}$ \\
\hline
\end{tabular}

The gestational age also statistically significantly correlated with length, head circumference, chest circumference and foot length. All the parameters showed a positive correlation coefficient ( $r$-value). The maximum correlation was observed with length ( $r$-value $=0.853)$ followed by foot length ( $r$ value $=0.809)$ (Table 4).

Table-5: Mean comparison of the anthropometric variables of the neonates according to the birth weight category and gestational age category. 


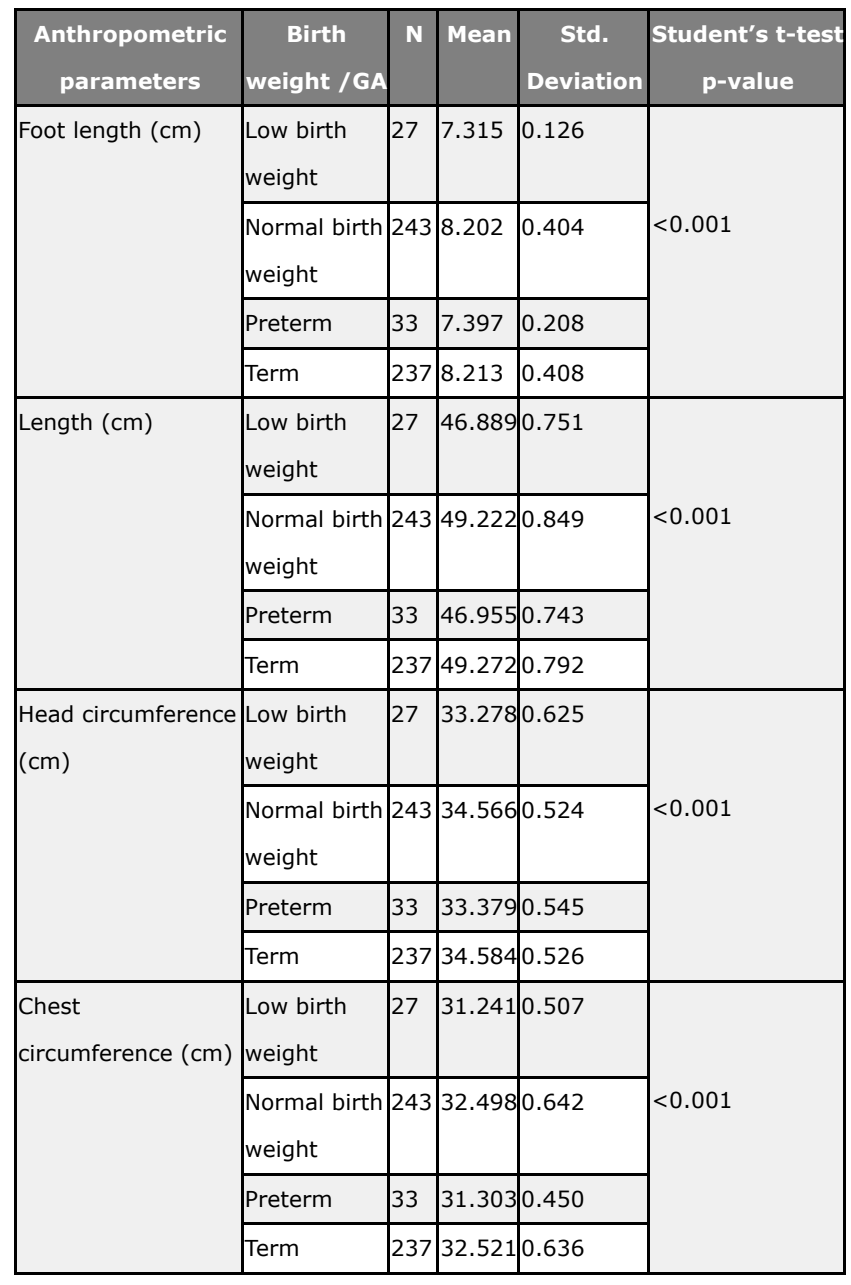

The student's unpaired t-test was used to compare the mean values of anthropometric variables of the neonates namely foot length, length, head circumference and chest circumference. The mean values of foot length, length, head circumference and chest circumference were statistically significantly higher among in normal weight babies compared to low-birth-weight babies with a p-value $(<0.001)$ and statistically significantly higher in term babies when compared to preterm babies.

Table-6: Correlation between foot length and other anthropometric parameters and gestational age.

\begin{tabular}{|c|c|c|c|c|}
\hline Parameters & $\begin{array}{l}\text { Number of } \\
\text { subjects }\end{array}$ & $\begin{array}{c}\text { Correlation } \\
\text { (r) }\end{array}$ & $\begin{array}{c}\text { R-square } \\
\text { (r2) }\end{array}$ & $\begin{array}{c}\mathrm{P} \\
\text { value }\end{array}$ \\
\hline Birth weight $(\mathrm{kg})$ & 270 & 0.905 & 0.819 & $\begin{array}{l}<0.00 \\
1\end{array}$ \\
\hline Length $(\mathrm{cm})$ & 270 & 0.786 & 0.618 & $\begin{array}{l}<0.00 \\
1\end{array}$ \\
\hline $\begin{array}{l}\text { Head circumference } \\
(\mathrm{cm})\end{array}$ & 270 & 0.719 & 0.517 & $\begin{array}{l}<0.00 \\
1\end{array}$ \\
\hline $\begin{array}{l}\text { Chest circumference } \\
(\mathrm{cm})\end{array}$ & 270 & 0.603 & 0.364 & $\begin{array}{l}<0.00 \\
1\end{array}$ \\
\hline $\begin{array}{l}\text { Gestational age } \\
\text { (weeks) }\end{array}$ & 270 & 0.809 & 0.654 & $\begin{array}{l}<0.00 \\
1\end{array}$ \\
\hline
\end{tabular}

The foot length showed a statistically significant correlation with birth weight, length, head circumference, chest circumference and gestational age. All the parameters showed a positive correlation coefficient ( $r$-value). The maximum correlation was observed with birth weight ( $r$ value $=0.905)$ followed by gestational age ( $r$ value $=0.809)$ (Table 6)

\section{Discussion}

The early identification of preterm and low birth weight babies is important to initiate any measures to reduce morbidity and mortality among newborn babies. There are various ways to assess the growth of the newborn. The present study was done to find the utility of using newborn foot length as a screening tool to identify LBW/Preterm babies. Out of the 270 neonates, $58.5 \%$ were male babies and $41.5 \%$ were female babies. In the present study, males neonates were more than female neonates similar findings were seen in Mukherjee et male babies were $54.1 \%$ and female babies were $45.9 \%$ [6]. In the present study, the mean birth weight of the neonates was $2.948 \pm 0.344 \mathrm{~kg}$ which ranged from $2.050 \mathrm{~kg}$ to $3.750 \mathrm{~kg}$ similarly Elizabeth et al found the mean birth weight to be $3.050 \pm 0.53 \mathrm{~kg}$ [7].

In the present study, $10 \%$ of the neonates were found to have low birth weight $(<2.5 \mathrm{~kg})$ and $90 \%$ of the neonates had normal birth weight similarly Elizabeth et al observed $12 \%$ babies having LBW $(<2.5 \mathrm{~kg}$ ) (7). According to NFHS-4 (National Family Health Survey of 2015-2016), the prevalence of LBW was $16.4 \%$ in India [8].

In this study, the mean gestational age of the neonates was $38.432 \pm 1.395$ weeks which ranged from 34.286 weeks to 41.286 weeks. Mukherjee et al observed that mean gestational was $36.37 \pm 3.6$ weeks [6]. In the present study, $12.2 \%$ of the neonates were found to be preterm babies and $87.8 \%$ of the neonates were term babies. Rakkappan et al did a study in Tamil Nadu and identified $18.6 \%$ babies as preterm [9] Ahankari et al observed $6.1 \%$ of babies were preterm [10].

In the present study, the mean foot length was $8.113 \pm 0.468 \mathrm{~cm}$ which ranged from 7.100 to 8.900 $\mathrm{cm}$. This is comparable to other studies. Marchant et al observed that the mean foot length was 7.8 0.4 $\mathrm{cm}$ [11]. Taksande et al found the mean foot length

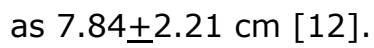


In the present study, the mean foot length among LBW and normal-weight babies was $7.315 \pm 0.126$ and $8.202 \pm 0.404$ respectively. The mean foot length among preterm and term babies was $7.397 \pm 0.208$ and $8.213 \pm 0.403$ respectively. Similar differences were observed in Rakkappan et al the mean foot length for the term and pre-term babies were $6.91 \pm 0.44 \mathrm{~cm}$ and $5.94 \pm 0.43 \mathrm{~cm}$ respectively [7] and Mullany et al mean foot length was $6.8 \pm 0.4$ $\mathrm{cm}$ and $7.3 \pm 0.3 \mathrm{~cm}$ among LBW and normal-weight babies respectively [13].

The mean values of other anthropometric variables in the present study were as follows: length $48.989 \pm 1.093 \mathrm{~cm}$; head circumference $34.437 \pm 0.659 \mathrm{~cm}$ and chest circumference $32.372 \pm 0.734 \mathrm{~cm}$. These findings are comparable to other study findings. Sreeramareddy et al observed the mean values of anthropometric variables: head circumference $34.6 \pm 1.5 \mathrm{~cm}$ and chest circumference $32.8 \pm 1.9 \mathrm{~cm} \mathrm{[14]}$.

In the present study, the foot length was statistically significantly correlated with birth weight, length, head circumference, chest circumference and gestational age. All the parameters showed a positive correlation coefficient ( $r$-value). The maximum correlation was observed with birth weight $(r$-value $=0.905)$ followed by gestational age (r-value $=0.809)$, length ( $r$ value $=0.786)$, head circumference $(r$-value $=0.719)$ and chest circumference $(r$-value $=0.603)$. Similar significant correlations were seen in other studies. Srinivasa et al observed that the correlation coefficient between foot length and other anthropometric variables such as BW, GA, HC, CC and length was $0.9,0.87,0.86,0.81$ and 0.84 respectively [15].

In the present study, the foot length was statistically significantly correlated with birth weight, length, head circumference, chest circumference and gestational age. All the parameters showed a positive correlation coefficient ( $r$-value). The maximum correlation was observed with birth weight $(r$-value $=0.905)$ followed by gestational age (r-value $=0.809)$, length ( $r$ value $=0.786)$, head circumference $(r$-value $=0.719)$ and chest circumference $(r$-value $=0.603)$. Similar significant correlations were seen in other studies. Gavhane et al did a study in Aurangabad and found that the foot length had a significant correlation with gestational age and other anthropometric variables in term and preterm infants [16].
Wyk et al in South Africa observed a significant correlation between foot length and gestational age $(r=0.887)$, birth weight $(r=0.920)$, length $(r=0.906)$ and head circumference $(r=0.903)$ [17].

\section{Conclusion}

Foot length had a significant correlation with birth weight and gestational age of the neonates. Foot length also correlated significantly with other anthropometric variables like length, head circumference and chest circumference.

\section{What does the study add to the existing knowledge?}

Foot length is a simple, practicable, quick and reliable tool for anthropometric measurement with minimal handling of the neonate. It can be used as a proxy measurement for assessing low birth weight and preterm babies in the community and can be easily measured by paramedical workers to detect neonates who are low birth weight and preterm babies.

\section{Author contribution} Dr. Abhinaya Arun Raj: Study design, data
collection

Dr. K. Maheswari: Data analysis and interpretation of results

\section{Reference}

01 . Newborns- reducing mortality [Internet]. [cited 2020 Aug 2].

Available from: [Article] [Crossref]

02. Kramer MS. Determinants of low birth weightmethodological assessment and meta-analysis. Bull World Health Organ. 1987;65(5)663-737. [Crossref]

03. WHO. The world health report 1995 - bridging the gaps [Internet]. WHO- World Health Organization. [cited 2020 Aug 2].

Available from: [Article] [Crossref]

04. Andersen HF, Johnson TR, Barclay ML, Flora JD. Gestational age assessment- I, analysis of individual clinical observations. Am J Obstet Gynecol. 1981;139(2)173-177.

doi: $\quad 10.1016 / 0002-9378(81) 90441-5 \quad$ [Crossref] 
05. Ballard JL, Khoury JC, Wedig KL, Wang L, EilersWalsman BL, Lipp R. New Ballard Score, expanded to include extremely premature infants. J Pediatr. 1991;119(3)417-423.

doi: $\quad 10.1016 /$ S0022-3476(05)82056-6 [Crossref]

06. Mukherjee S, Roy P, Mitra S, Samanta M, Chatterjee $S$. Measuring New-Born Foot Length to Identify Small Babies in Need of Extra Care- a Cross-Sectional Hospital Based Study. Iran J Pediatr. 2013;23(5)508-512.

[Crossref]

07. Elizabeth NL, Christopher OG, Patrick K. Determining an anthropometric surrogate measure for identifying low birth weight babies in Uganda- a hospital-based cross-sectional study. BMC Pediatr. 2013;13;54.

doi: 10.1186/1471-2431-13-54 [Crossref]

08. Khan N, Mozumdar A, Kaur S. Determinants of low birth weight in India- An investigation from the National Family Health Survey. Am J Hum Biol. 2020;32(3)e23355.

doi: 10.1002/ajhb.23355 [Crossref]

09. Rakkappan I, Kuppusamy N. Newborn Foot Length Measurement to Identify High-risk Neonate. Int J Sci Stud. 2016;4(2)13-19.

doi: 10.17354/ijss/2016/243 [Crossref]

10. Ahankari A, Bapat S, Myles P, Fogarty A, Tata L. Factors associated with preterm delivery and low birth weight- a study from rural Maharashtra, India. F1000 Res. 2017;6;72-72.

doi: 10.12688/f1000research. 10659.1 [Crossref]

11. Marchant T, Jaribu J, Penfold S, Tanner M, Armstrong Schellenberg J. Measuring newborn foot length to identify small babies in need of extra care- a cross sectional hospital-based study with community follow-up in Tanzania. BMC Public Health. 2010;10;624. doi: 10.1186/1471-2458-10-624 [Crossref]
12. Taksande A. Neonatal Foot Length- An Alternative Predictor of Low-Birth-Weight Babies in Rural India. Acad J Pediatr Neonatol. 2016; Aug 5;1;555-69.

doi: 10.19080/AJPN.2016.01.555569 [Crossref]

13. Mullany LC, Darmstadt GL, Khatry SK, Leclerq SC, Tielsch JM. Relationship between the surrogate anthropometric measures, foot length and chest circumference and birth weight among newborns of Sarlahi, Nepal. Eur J Clin Nutr. 2007;61(1)40-46.

doi: 10.1038/sj.ejcn.1602504 [Crossref]

14. Sreeramareddy CT, Chuni N, Patil R, Singh D, Shakya B. Anthropometric surrogates to identify low birth weight Nepalese newborns- a hospitalbased study. BMC Pediatr. 2008;8;16.

doi: 10.1186/1471-2431-8-16 [Crossref]

15. Srinivasa S, Manasa G, Madhu G. Foot length of newborn- Its correlation with gestational age and various anthropometric parameters. Curr Pediatr Res. 2017;21(2)248-253.

Available at [Article] [Crossref]

16. Wyk LV, Smith J. Postnatal Foot Length to Determine Gestational Age- A Pilot Study. J Trop Pediatr. 2016;62(2)144-151.

[Crossref]

17. Gavhane S, Kale A, Golawankar A, Sangle A. Correlation of foot length and gestational maturity in neonates. Int $\mathrm{J}$ Contemp Pediatr. 2016;3(3)705-708.

doi: 10.18203/2349-3291.ijcp20162212 [Crossref] 